\title{
Differences between Impulsive and Non-Impulsive Suicide Attempts among Individuals Treated in Emergency Rooms of South Korea
}

\author{
Meerae Lim¹, Soojung Lee ${ }^{2}$, and Jong-lk Park ${ }^{2,3 凶}$ \\ 'St. Andrea Neuropsychiatric Hospital, Icheon, Republic of Korea \\ ${ }^{2}$ Korea Suicide Prevention Center, Seoul, Republic of Korea \\ ${ }^{3}$ Department of Psychiatry, Kangwon National University School of Medicine, Chuncheon, Republic of Korea
}

\begin{abstract}
Objective A considerable proportion of suicide attempts are the result of sudden desires. Understanding such impulsive suicide attempts is necessary for effective interventions. We evaluated the impulsivity of suicide attempters treated in emergency rooms. The aim of the study was to identify the characteristics of impulsive suicide attempts by comparing these individuals to those who attempted to commit suicide in a non-impulsive manner.

Methods This study analyzed suicide attempters who visited the emergency departments of seven selected university hospitals. A total of 269 medical records in which impulsivity of suicide attempt were confirmed were subject to be analyzed. The impulsivity of the suicide attempt was examined using a summative score of items 6 and 15 on the Suicide Intent Scale.

Results A total of $48.0 \%$ of the participants were impelled by sudden inclinations to attempt suicide. Impulsive attempters were younger, unmarried and less physical illness than non-impulsive attempters, whereas no significant differences were found on psychiatric history and previous suicide history. Impulsive suicide attempters had suicide ideations that were not as severe $\left(\chi^{2}=55.33, \mathrm{p}<0.001\right)$ or intense $(\mathrm{t}=-8.38, \mathrm{p}<0.001)$ as their counterparts. Furthermore, medical results of impulsive suicide attempts were better than non-impulsive suicide attempts $(\mathrm{t}=-3.77, \mathrm{p}<0.001)$.

Conclusion The results suggested that a considerable proportion of suicide attempts were the result of sudden inclinations. Impulsive attempts were made in relatively earlier stages of suicide ideation; consequently, they have less intent than non-impulsive attempts.
\end{abstract}

Psychiatry Investig 2016;13(4):389-396

Key Words Suicide, Suicide attempt, Impulsivity, Impulsiveness, Suicide intent scale.

\section{INTRODUCTION}

Suicide is a major health problem worldwide and, presently, poses an extremely serious problem in Korea. Statistics Korea published data that indicate 14,160 individuals committed suicide in 2012 with the average suicide rate of 29.1 suicides per 100,000 persons. In the same year, Korea had the highest suicide rate among the Organization for Economic Co-operation and Development (OECD) member countries. ${ }^{1}$ The lifetime prevalence of suicide ideation, plan, and attempt in Korea were $15.2 \%, 3.3 \%$, and $3.2 \%$ respectively. ${ }^{2}$

Received: June 22, 2015 Revised: October 19, 2015

Accepted: November 8, 2015 Available online: March 23, 2016

$\triangle$ Correspondence: Jong-Ik Park, MD, PhD, LLM

Department of Psychiatry, Kangwon National University School of Medicine, Advisor at Korea Suicide Prevention Center, 1 Kangwondaehak-gil, Chuncheon 24341, Korea

Tel: +82-33-258-9171, Fax: +82-33-258-2146, E-mail: lugar@kangwon.ac.kr

(c) This is an Open Access article distributed under the terms of the Creative Commons Attribution Non-Commercial License (http://creativecommons.org/licenses/bync/3.0) which permits unrestricted non-commercial use, distribution, and reproduction in any medium, provided the original work is properly cited.
Generally, attempted suicides are 10 to 20 times more frequent than fatal suicides, ${ }^{3}$ and a considerable number of these attempts are impulsive. ${ }^{4-13}$ Recent studies conducted in Korea showed that $36.1-85.3 \%$ of suicide attempts were initiated impulsively. ${ }^{14,15}$ Studies on suicides in Asia suggested that impulsive suicide attempts, when coupled with the availability of fatal suicide methods, can increase regional suicide rates. ${ }^{3}$

Suicide prevention strategies are usually based on the theory that, when suicidal ideation intensifies significantly, ideation progresses to suicide planning, and eventually ends up with a suicide attempt. ${ }^{13,16,17}$ In other words, the first step of suicide prevention is the identification of at-risk individuals at each stage (i.e., suicide ideation, planning, and attempt); the second is an intervention to prevent people from progressing to the next stage. However, if numerous people do not follow this template, and instead impulsively attempt suicide at, or even prior to, the suicidal ideation stage, then intervention policies catered towards this population are necessary. In order to develop national strategies for reducing impetuous suicide 
attempts, characteristic differences between impulsive and premeditated suicide attempters should be identified and understood.

On the other hand, defining of impulsivity of suicide attempt is difficult. ${ }^{18}$ Some researchers defined impulsivity of suicide attempt using duration from first ideation to their attempt. ${ }^{13,19}$ Whereas other researchers defined as absence of proximal planning or preparations. ${ }^{6,20,21}$ In this case, many studies used all or some items of Suicide Intent Scale (SIS). ${ }^{22}$

In this study, we tried to evaluate the impulsivity of suicide attempts that led to emergency room treatments. We also investigated the characteristics of suicide attempters in impulsive way (those who attempted suicide without any planning) by comparing these characteristics with those of non-impulsive suicide attempters (those who attempted suicide with planning).

The impulsivity discussed in this study only referred to characteristics about way of suicide attempts. Therefore, "impulsive attempter" does not mean that the suicide attempters were more impulsive than others, but rather that their attempted acts were more impulsive. In fact, one study indicated that the impulsivity of suicide attempters and that of their suicide attempts are not significantly correlated. ${ }^{4,23}$ There were also some definitions of impulsive suicide attempt made by other researchers. ${ }^{18,24}$ Despite of controversy related to impulsivity, we operatively defined impulsive suicide attempt in terms of a lack of proximal planning and/or premeditation.

\section{METHODS}

\section{Study design}

This study reviewed data, collected under Article 11 of the Suicide Prevention Act (a survey assessing suicide conducted every 5 years in Republic of Korea), ${ }^{25}$ on nationwide suicide attempts that occurred between July 6, 2012, and November 25,2012 . The national survey on suicide attempts was planned, managed, and directed by the Korean Suicide Prevention Center (KSPC). This organization was the nucleus of a network consisting of seven national hospitals, including the Boramae Medical Center, Seoul National University Bundang Hospital, Kangwon National University Hospital, Eulji University Hospital, Chonnam National University Hospital, Pusan National University Hospital, and Gyeongsang National University Hospital. The KSPC developed a tool for assessing suicide attempters visiting emergency departments for their selfinjurious acts. The organization distributed this assessment tool to the seven network hospitals and educated them in its use. The network hospitals' Psychiatrists and psychiatric residents in seven network hospitals interviewed the admitted suicide attempters using the KSPC assessment tool. The policy for selecting interviewees depended on the suicide attempters' conscious states: attempters were interviewed if they were conscious and could communicate, and their family members were approached if they were not. We recorded the contents of the patients' interviews on their medical records, and analyzed these data retrospectively. This study was approved by each network hospitals Institutional Review Board.

\section{Study participants}

We analyzed the medical records of suicide attempters who visited the seven network hospitals at any time between July 6, 2012, and November 25, 2012. A suicide attempt comprised "a self-destructive behavior with intent to end one's life independent of resulting damage".26 Records of individuals who passed away prior to hospital arrival were exempt from the analysis.

Of the 502 medical records collected through the nationwide survey on suicide, our study only included the medical records of 269 patients whose suicide attempt's impulsivity could be determined. The remaining 233 medical records were exempted from this study, because impulsivity on these cases was unable to be determined. However, there were no significant differences between the two groups in their demographics, such as age range $(t=0.60, p=0.55)$, gender $\left(\chi^{2}=1.18\right.$, $\mathrm{p}=0.28)$, marital status $\left(\chi^{2}=3.50, \mathrm{p}=0.62\right)$, cohabitant $\left(\chi^{2}=\right.$ $4.54, \mathrm{p}=0.21)$, and educational background $\left(\chi^{2}=9.31, \mathrm{p}=0.05\right)$.

\section{Evaluation tools}

The tool for assessing suicide attempters visiting emergency departments was developed by KSPC. The tool consisted of sociodemographic data (age, sex, marital state, socioeconomic status, etc.) and factors related to suicide attempt (reason, method, etc.). We used Suicide Intent Scale (SIS) and Colombia Suicide Severity Rating Scale (C-SSRS).

\section{Suicide Intent Scale}

For the last 30 years, the SIS ${ }^{22,27}$ has been the most widely used suicide intention measurement tool. The SIS contains 15 questions, each of which is rated on a scale from 0 to 2 , giving a total score range of $0-30$. Korean version of SIS was used in this study and Cronbach's alpha was 0.84 .

Impulsivity of suicide attempts was measured as the sum of SIS item 6, "degree of planning" and item 15, "degree of premeditation", ${ }^{6,21}$ The sum of items 6 and 15 ranged from 0 to 4 . We divided study participants into two groups based on the impulsivity of their suicide attempts. Those whose score was 0 joined the impulsive group, and those who scored 2-4, joined the non-impulsive group. Medical records of patients who scored 1 were exempted from the comparative analysis.

We also used total scores of SIS to measure suicide intent. 
Because we divided suicide attempters group based on SIS 6 and 15 items, we excluded those two items in calculating total SIS score. Therefore SIS total score in this study ranged from 0 to 26 .

\section{Colombia Suicide Severity Rating Scale}

In order to evaluate suicide ideation and behavior objectively and systematically, researchers from Columbia University, the University of Pennsylvania, and the University of Pittsburgh created C-SSRS. ${ }^{28}$ The research team translated the rating scale into many languages, including Korean, to allow for wide distribution. In this study, we assessed current suicide ideation and behavior with C-SSRS.

The C-SSRS consists of two sections: suicide ideation and suicide behavior. Both contain two categories: the former, severity and intensity; the latter, suicide behavior and suicide lethality. There are, therefore, a total of four C-SSRS categories. The severity subscale is rated on a 5-point ordinal scale, from 1 (wish to be dead) and 5 (suicidal intent with plan). Intensity of suicide ideation (intensity subscale) is measured in five different aspects, each rated on a 5-point ordinal scale: frequency; duration; controllability; and deterrents of, and reasons for, ideation. Suicide behavior (a behavior subscale) is rated on a nominal scale that includes actual, interrupted attempt, and aborted attempts, as well as preparatory behavior, and non-suicidal self-injurious behavior. The actual lethality of a suicide attempt (lethality subscale) is scored on a 6-point ordinal scale: 0 (no physical damage) to 5 (death).

\section{Causes of suicide}

For analytic purposes, causes of suicide attempts were classified as either stress or psychiatric symptoms. Causes were evaluated twice; subjectively, by the suicide attempters, and objectively, following an interview, by a psychiatrist. In the subjective analysis, multiple causes could be selected. However, in the objective analysis, only one cause-that which was closest to the attempter's reason-could be selected. Causes attributing to self-injurious acts of all suicide attempters have already been analyzed by Lim et al. ${ }^{29}$

\section{Statistical analysis}

Psychiatrists or psychiatric residents reviewed medical records and made coding data. We analyzed the data using SPSS 18.0 for Windows (SPSS Inc., Chicago, IL, USA). To identify the basic characteristics of the participants, we conducted a primary descriptive analysis. We assessed group differences for continuous variables that fit a normal distribution using t-tests and for non-parametric variables, Mann-Whitney test was applied; for categorical variables, we employed the chisquare test. Covariates were corrected using the Mantel-
Haenszel test, logistic regression and analysis of covariance (ANCOVA). Probability (p) values less than 0.05 were deemed to be statistically significant.

\section{RESULTS}

\section{Suicide attempters: demographic characteristics and the consequences of suicide attempts}

The participants' ages averaged $42.6 \pm 19.49$, and ranged from 13 to 95 years. There were more females (163 participants, 60.6\%) than males (106 participants, 39.4\%). Average age was $45.9 \pm 19.02$ for males, and $40.5 \pm 17.87$ for females; this difference was significant $(t=2.35, p=0.02)$. A summary of participant demographics is available in Table 1.

A total of 235 participants (87.7\%) chose stress, and 53 participants (19.8\%) chose psychiatric symptoms as the main causes of their attempts. Objective analysis by interviewers indicated stress was the reason for attempting suicide among 147 participants (57.0\%), and psychiatric symptoms, in 110 (42.6\%). When evaluated using C-SSRS, severity of suicide ideation averaged $3.82 \pm 1.24$ points, and intensity of suicide ideation averaged $14.22 \pm 3.43$ points. The SIS intent scores were 10.57 points \pm 5.77 .

Drug poisoning was the most frequently employed suicide method, figuring in the cases of 158 participants (59.0\%). Pesticipide poisoning was used by 43 participants $(16.0 \%)$; weaspons, such as knives, by 29 (10.8\%); and suffocation, by 13 (4.9\%). Poisoning by gases and other substanstances was the chosen method for 10 participants (3.7\%). Five participant (1.9\%) tried to commit suicide by jumping.

When they arrived at the emergency departments, 157 participants (58.8\%) were alert, and 48 particapants (18.0\%) were in a reduced state of consciousness, but were verbally reponsive. A total of 48 participants (18.0\%) experienced reduced consciouness and were responsive only to pain, and 6 particpants (2.2\%) arrived at the emergency room unconscious.

The severity of the medical injuries was evaluated using the C-SSRS lethality subscale. One participant's injury (0.4\%) led to death. Seven (2.8\%) participants had severe injuries that required hospitalization with intensive care, 35 (14.2\%) had moderately severe injuries that led to hospitalization, 88 (25.6\%) exhibited moderate injuiries that required medical attention, 87 (53.2\%) were minor injuries, and 29 (11.7\%) were very minor.

\section{Socio-demographic characteristics of impulsive and non-impulsive suicide attempters}

The sum score of SIS items 6 and 15 was used to identify the participants according to the impulsive nature of their sui- 
Table 1. Demographic characteristics of the subjects

\begin{tabular}{|c|c|c|c|c|c|c|}
\hline & $\begin{array}{l}\text { Total subjects } \\
\qquad(\mathrm{N}=269)\end{array}$ & $\begin{array}{l}\text { Impulsive attempters } \\
\qquad(\mathrm{N}=129)\end{array}$ & $\begin{array}{c}\text { Planned attempters } \\
(\mathrm{N}=93)\end{array}$ & Statistics & df & $\mathrm{p}$ \\
\hline$\overline{\text { Age }^{\dagger}}$ & $42.59( \pm 18.49)$ & $40.4( \pm 18.51)$ & $46.6( \pm 17.99)$ & -2.47 & 220 & $0.01^{*}$ \\
\hline Sex ${ }^{\ddagger}$ (female $\left.\%\right)$ & $163(60.6 \%)$ & $84(65.1 \%)$ & $54(58.1 \%)$ & 1.14 & 1 & 0.28 \\
\hline Degree of education ${ }^{\ddagger}$ (year) & & & & 1.76 & 4 & 0.78 \\
\hline $0-5$ & $15(5.8 \%)$ & $5(4.0 \%)$ & $15(4.5 \%)$ & & & \\
\hline $6-8$ & $27(10.4 \%)$ & $17(13.6 \%)$ & $35(10.6 \%)$ & & & \\
\hline $9-11$ & $43(16.6 \%)$ & $19(15.2 \%)$ & $57(17.3 \%)$ & & & \\
\hline $12-15$ & $103(39.8 \%)$ & $48(38.4 \%)$ & $140(42.4 \%)$ & & & \\
\hline $16-$ & $71(27.4 \%)$ & $36(28.8 \%)$ & $83(25.2 \%)$ & & & \\
\hline Marital state ${ }^{\ddagger}(\%)$ & & & & 13.43 & 2 & $<0.01^{* *}$ \\
\hline Unmarried & $94(35.2 \%)$ & $53(41.4 \%)$ & $22(23.9 \%)$ & & & \\
\hline Married & $137(51.3 \%)$ & $65(50.8 \%)$ & $49(53.3 \%)$ & & & \\
\hline Separated, Divorced, Bereaved & $36(13.5 \%)$ & $10(7.8 \%)$ & $21(22.8 \%)$ & & & \\
\hline Living arrangements (\%) $^{\prime}$ & & & & 7.68 & 3 & 0.05 \\
\hline Living with family & $213(80.4 \%)$ & $109(84.5 \%)$ & $69(75.8 \%)$ & & & \\
\hline Living with other than family & $8(3.0 \%)$ & $6(4.7 \%)$ & $1(1.1 \%)$ & & & \\
\hline Dormitory or residential facility & $3(1.1 \%)$ & $1(0.8 \%)$ & $2(2.2 \%)$ & & & \\
\hline Living alone & $41(15.5 \%)$ & $13(10.1 \%)$ & $19(20.9 \%)$ & & & \\
\hline Household income (thousand KRW) $^{\text {. }}$ & $2,654( \pm 2,399)$ & $2,774( \pm 2,463)$ & $2,474( \pm 2,348)$ & 4123.0 & & 0.38 \\
\hline Religion ${ }^{\ddagger}(\%)$ & & & & 0.19 & 1 & 0.28 \\
\hline Present & $102(41.5 \%)$ & $43(37.1 \%)$ & $38(44.7 \%)$ & & & \\
\hline Absent & $144(58.5 \%)$ & $73(62.9 \%)$ & $47(55.3 \%)$ & & & \\
\hline Physical illness ${ }^{\ddagger}$ (\%) & & & & 4.47 & 1 & $0.04^{*}$ \\
\hline Present & $79(30.2 \%)$ & $32(25.4 \%)$ & $35(38.9 \%)$ & & & \\
\hline Absent & $183(69.8 \%)$ & $94(74.6 \%)$ & $55(61.1 \%)$ & & & \\
\hline Psychiatric treatment history ${ }^{\ddagger}(\%)$ & & & & 0.21 & 1 & 0.65 \\
\hline Present & $137(50.9 \%)$ & $68(53.1 \%)$ & $46(50.0 \%)$ & & & \\
\hline Absent & $127(47.2 \%)$ & $60(46.9 \%)$ & $46(50.0 \%)$ & & & \\
\hline Previous suicide attempt history $\ddagger$ (\%) & & & & 1.28 & 1 & 0.26 \\
\hline Present & $83(31.2 \%)$ & $39(30.7 \%)$ & $35(38.0 \%)$ & & & \\
\hline Absent & $183(68.8 \%)$ & $88(69.3 \%)$ & $57(62.0 \%)$ & & & \\
\hline
\end{tabular}

${ }^{*} \mathrm{p}<0.05,{ }^{* *} \mathrm{p}<0.01,{ }^{\dagger} \mathrm{t}$-tests was performed, ${ }^{\ddagger}$ chi-square test was performed, ${ }^{\S}$ Mann-Whitney tests was performed

cide attempts. From a total of 269 participants, 129 (48.0\%) had a summative score of 0 and were consequently categorized as impulsive suicide attempters; 93 (34.6\%) had sums ranging from 2 to 4 , and were identified as non-impulsive suicide attempters; 47 participants had a summative score of 1 , and were not analyzed further.

Demographic characteristics of the two different types of suicide attempters are summarized in Table 1. Impulsive suicide attempters were significantly younger $(t=-2.47, \mathrm{p}=0.01)$ than non-impulsive attempters; their average age were $40.4 \pm$ 18.51 and $46.6 \pm 17.99$ respectively. The percentage of women in the impulsive suicide attempt group was $65.1 \%$, and $58.1 \%$ in the non-impulsive group. This difference was not significant $\left(\chi^{2}=1.14, p=0.29\right)$. Educational background $\left(\chi^{2}=1.76, p=\right.$ $0.78)$, and the presence of religious beliefs $\left(\chi^{2}=1.19, p=0.28\right)$ were not significantly different between the two groups.
Marital status differed significantly between the two groups $\left(\chi^{2}=13.43, p<0.001\right)$. In the impulsive suicide attempt group, the greatest proportion of individuals were unmarried $\left(\chi^{2}=7.29\right.$, $\mathrm{p}=0.02)$. The majority in the non-impulsive attempt group was divorced, separated, or bereaved $\left(\chi^{2}=9.97, p=0.01\right)$. Once the ages of the participants were adjusted, whether one was single was not significantly different $\left(\chi^{2}{ }_{M H}=0.16, p=0.70\right)$ between the two groups. However, the differences between the groups persisted $\left(\chi_{\mathrm{MH}}^{2}=5.81, \mathrm{p}=0.02\right)$ in patients who were divorced, separated, or bereaved. A lower percentage of impulsive suicide attempters than planned suicide attempters lived alone $\left(\chi^{2}=5.01, \mathrm{p}=0.02\right)$.

Although the proportion of patients with physical illnesses was significantly different $\left(\chi^{2}=4.47, \mathrm{p}=0.04\right)$ between the two groups, when age was adjusted using logistic regression analysis, no significant difference [OR: 1.497, 95\% CI (0.719-3.118)] 
emerged. Histories of mental illness and previous suicide attempts were not significantly different $\left(\chi^{2}=1.28, p=0.26\right)$ between the impulsive group and the non-impulsive group.

\section{Reasons and ideation in suicide of impulsive and non-impulsive groups}

In subjective assessments, $14.1 \%$ of the impulsive and $26.9 \%$ of the non-impulsive groups chose psychiatric symptoms as the cause for their suicide attempts. The differences between the two were significant $\left(\chi^{2}=5.65, p=0.02\right)$. However, $86.7 \%$ of the impulsive group and $89.2 \%$ of the non-impulsive group selected stress as a cause of their suicide attempts, which did not yield a significant difference $\left(\chi^{2}=0.32, p=0.57\right)$.

In objective assessments, 78 (63.4\%) impulsive suicide attempters appeared to be triggered by stress and 45 (36.6\%) by psychiatric symptoms. With regard to non-impulsive suicide attempters, 46 (51.7\%) seemed to be triggered by stress, and 43 (48.3\%) by psychiatric symptoms. While a greater proportion of impulsive suicide attempters were affected by stress, there was no significant association between the two groups and the causes of suicide attempts $\left(\chi^{2}=2.92, p=0.09\right)$.
Table 2 shows the severity of suicide ideations in both groups, when evaluated using the C-SSRS. Compared to their non-impulsive counterparts $(4.43 \pm 0.94)$, impulsive suicide attempters $(3.29 \pm 1.25)$ had less severe ideations of suicide $(\mathrm{t}=$ $-6.99, \mathrm{p}<0.001)$. To adjust age and sex as covariates, ANCOVA was used. The difference was also statistically significant $(\mathrm{F}=$ $19.55, \mathrm{p}<0.001)$. The intensity of suicide ideations was evaluated using C-SSRS. The impulsive group scored an average of $12.36 \pm 3.27$ points, which was significantly lower $(t=-8.38$, $\mathrm{p}<0.001)$ than the score of the non-impulsive group, which averaged $16.19 \pm 2.63$ points. To adjust age and sex as covariates, ANCOVA was used. The difference was also statistically significant $(\mathrm{F}=25.17, \mathrm{p}<0.001)$. The impulsive group scored lower on all five categories of suicide ideation. This meant incidence of suicide ideation was lower, duration of ideation was shorter, and individuals had greater control over their thoughts of suicide. In addition, impulsive suicide attempters had deterrents that helped them control their ideations. The reason for ideation was influenced more by the desire to change the environment rather than to end personal pain (frequency $t=-5.93$, $\mathrm{p}<0.001$; duration $\mathrm{t}=-6.25, \mathrm{p}<0.001$; controllability $\mathrm{t}=-3.56$,

Table 2. Comparison of suicide idea, method and lethality of suicide attempt between two groups

\begin{tabular}{|c|c|c|c|}
\hline & $\begin{array}{l}\text { Impulsive } \\
\text { attempters }\end{array}$ & $\begin{array}{c}\text { Non-impulsive } \\
\text { attempters }\end{array}$ & Total \\
\hline \multicolumn{4}{|l|}{ Severity of suicide idea (C-SSRS) } \\
\hline Wish to be dead & $12(12.6 \%)$ & $0(0.0 \%)$ & $12(6.6 \%)$ \\
\hline Non-specific active suicidal thoughts & $12(12.6 \%)$ & $8(9.1 \%)$ & $20(10.9 \%)$ \\
\hline Active suicide ideation with any methods (not plan) without intent to act & $22(23.2 \%)$ & $4(4.5 \%)$ & $26(14.2 \%)$ \\
\hline Active suicidal ideation with some intent to act, without specific plan & $34(35.8 \%)$ & $18(20 / 5 \%)$ & $52(28.4 \%)$ \\
\hline Active suicidal ideation with specific plan and intent & $15(15.8 \%)$ & $58(65.9 \%)$ & $73(39.9 \%)$ \\
\hline Total & $95(100.0 \%)$ & $88(100.0 \%)$ & $183(100.0 \%)$ \\
\hline \multicolumn{4}{|l|}{ Methods of suicide attempts } \\
\hline Drug intoxication & $85(63.0 \%)$ & $49(51.0 \%)$ & $134(58.0 \%)$ \\
\hline Pesticide or herbicide poisoning & $16(11.9 \%)$ & $19(19.8 \%)$ & $35(15.2 \%)$ \\
\hline Gas intoxication & $1(0.7 \%)$ & $10(10.4 \%)$ & $11(4.8 \%)$ \\
\hline Other chemical agents poisoning & $5(3.7 \%)$ & $2(2.1 \%)$ & $7(3.0 \%)$ \\
\hline Hanging & $3(2.2 \%)$ & $9(9.4 \%)$ & $12(5.2 \%)$ \\
\hline Stabbing & $23(17.0 \%)$ & $5(5.2 \%)$ & $28(12.2 \%)$ \\
\hline Falling & $2(1.5 \%)$ & $2(2.1 \%)$ & $4(1.7 \%)$ \\
\hline Total & $135(100.1 \%)$ & $96(100.0 \%)$ & $231(100.0 \%)$ \\
\hline \multicolumn{4}{|l|}{ Actual lethality of suicide attempt (C-SSRS) } \\
\hline No physical damage or very minor physical damage & $18(16.2 \%)$ & $7(7.6 \%)$ & $25(12.3 \%)$ \\
\hline Minor physical damage & $47(42.3 \%)$ & $25(27.2 \%)$ & $72(35.5 \%)$ \\
\hline Moderate physical damage; medical attention needed & $33(29.7 \%)$ & $37(40.2 \%)$ & $70(34.5 \%)$ \\
\hline $\begin{array}{l}\text { Moderately severe physical damage; medical hospitalization and } \\
\text { likely intensive care required }\end{array}$ & $12(10.8 \%)$ & $18(19.6 \%)$ & $30(14.8 \%)$ \\
\hline Severe physical damage; medical hospitalization with intensive care required & $1(0.9 \%)$ & $4(4.3 \%)$ & $5(2.5 \%)$ \\
\hline Death & $0(0.0 \%)$ & $1(1.1 \%)$ & $1(0.5 \%)$ \\
\hline Total & $111(100.0 \%)$ & $92(100.0 \%)$ & $203(100.0 \%)$ \\
\hline
\end{tabular}

C-SSRS : Colombia Suicide Severity Rating Scale 
$\mathrm{p}<0.001$; deterrents $\mathrm{t}=-2.69, \mathrm{p}=0.004$; reason for ideation $\mathrm{t}=$ $-4.08, \mathrm{p}<0.001)$.

\section{Suicidal behaviors of impulsive and non-impulsive suicide attempters}

Specific suicide methods of the two groups are summarized in mid- part of Table 2. Drug poisoning and self-inflicted injuries, like wrist cutting, were reclassified as nonfatal methods. Poisoning, including the use of pesticides and gas, suffocation, and jumping were reclassified as fatal methods. When analyzed under this classification, the impulsive group was less likely $\left(X^{2}=12.25, \mathrm{p}<0.001\right)$ to choose a fatal method of suicide: 27 patients $(21.1 \%)$ from the impulsive suicide group employed fatal methods, whereas $40(43.0 \%)$ from non-impulsive suicide group employed fatal methods.

Suicide intent was evaluated using the SIS. As we mentioned above, as we excluded item 6 and item 15, total SIS score ranged from 0 to 26 . The results indicated that impulsive suicide attempters had an average score of $6.87 \pm 4.43$ points, which was significantly lower $(t=-11.05, \mathrm{p}<0.001)$ than that of the non-impulsive group, which scored $13.15 \pm 3.81$ points.

Medical lethality of the suicide attempts that was evaluated using the C-SSRS lethality subscale is recorded in Table 2. When the C-SSRS points were employed in comparing lethality, impulsive suicide attempters were found to have less severe medically lethal injuries $(\mathrm{t}=-3.77, \mathrm{p}<0.001)$ than those in the non-impulsive group. To adjust age and sex as covariates, ANCOVA was used. The difference was also statistically significant $(\mathrm{F}=9.52, \mathrm{p}<0.001)$.

\section{DISCUSSION}

In this study, we examined the impulsivity of the 269 suicide attempters who visited the seven university hospitals' emergency rooms. This study analyzed impulsive suicide attempters' characteristics by comparing them to the characteristics of non-impulsive attempters. To our knowledge, this study is the first to objectively measure impulsive suicide attempts in Korea. Moreover, the strengths of this study was its use of an objective measurement tool to assess suicide ideations and suicide behaviors.

Of the 269 participants, 129 (48.0\%) did not plan their suicide (SIS item $6=0$ ) or have any prior premeditation of suicide (SIS item 15=0). This result differed from the findings of some Korean suicide studies. Jeon et al. ${ }^{15}$ reported that onethird of those with histories of suicide attempts committed suicide impulsively. On the other hand, Ha et al. ${ }^{14}$ reported that $85.3 \%$ of the suicide attempter patients visiting emergency departments were impelled by sudden inclinations. Such discrepancies may be due to the differences in research methods; specifically, in the evaluation of impulsivity. Jeon et al. studied a randomized sample from the general population and asked whether individuals had suicide ideations, plans, or attempts at any point in their lives. The participants who had suicide plans and attempts were placed in the planned suicide attempt group. Likewise, those who had attempted suicide previously without premeditated plans were placed in the impulsive suicide attempt group. Similar to the present study, Ha et al. sampled individuals who visited emergency departments after their suicide attempts. However, their study relied on the participant's subjective opinion in determining their suicides' impulsivity. In contrast, our study evaluated impulsivity using two different criteria: the attempter's subjective evaluation (item 15), and an objective evaluation based on the situation surrounding the suicide attempt (item 6). This study's more-stringent definition of impulsivity of suicide attempts may explain the lower rate of impulsive suicide attempts. A study by Suominen et al. ${ }^{21}$ used participants and a definition of impulsivity that most closely resembled our present research. Their study reported that $44.4 \%$ of suicide attempts were impulsive-similar to this study's results. Regardless of the evaluation criteria, a considerable proportion of suicides were attempted impulsively.

Impulsive suicide attempters, when compared to non-impulsive suicide attempters, had less severe and intense suicide ideations. This suggested that impulsive suicide attempters progressed from a vague suicide ideation step directly to a suicide attempt. Results of the SIS also revealed impulsive suicide attempters to have significantly lower intents than those of non-impulsive suicide attempters. The suicide methods selected by the impulsive attempters were also significantly less lethal than those chosen by non-impulsive suicide attempters. The medical results assessed using the C-SSRS lethality subscale also revealed that impulsive attempters had relatively less-lethal injuries than their counterparts. This was consistent with the results of other studies; ${ }^{4,20,21,30}$ planned suicide attempters have, therefore, a greater risk of suicide.

The present results indicated that compared to their nonimpulsive counterparts, impulsive suicide attempters were relatively younger, and few of them were widowed, separated, or divorced. A only small proportion of them lived alone. These results were consistent with the fact that risks of suicide tend to increase in individuals who are older, solitary living, divorced, etc. ${ }^{31-34}$

Psychiatric symptoms, as the main reason for suicide attempts, were more common in the non-impulsive suicide group. This result was consistent with previous findings that indicated a smaller proportion of impulsive suicide attempters had psychiatric symptoms, and that the symptoms are were less severe. ${ }^{13,20,21}$ 
Impulsive suicide attempters were at less risk than their nonimpulsive counterparts. However, $21.1 \%$ of the impulsive suicide attempters still employed lethal methods. While the percentage of those that employed lethal methods was low compared to the non-impulsive group, approximately onefifth of impulsive suicide attempters used methods that could have had led to death. In fact, $11.7 \%$ of impulsive suicide attempters had injuries that were severe enough to require hospitalization. Considering relatively higher proportion of impulsive attempt in young age, we should not ignore suicide ideation, regardless of severity, at earlier stage. Additionally, in order to reduce the incidence of death by impulsive suicide, lethal suicide methods, which can be encountered when one feels sudden inclinations to commit suicide, should be less accessible. . $^{3,35-38}$

The concept or definition of impulsivity of suicide has been confusingly applied in clinical setting and frequently ignored for evaluation in Korea, so it should be investigated more comprehensively to prevent suicide reattempts after discharged from emergency room.

\section{Limitations}

This study had a few limitations, with the first being the representativeness of the study participants. Data collected from a national hospital network were used, but the network only consisted of university hospitals. Thus, participants of this study were suicide attempters who visited university hospitals and, consequently, selection bias could not be avoided. Not all suicide attempts were treated at university hospitals, so hospitals involved in this study may not be a fair representation of their regions. However, small hospitals within these regions have very few emergency room visitors. In order to collect satisfactory numbers of participants, this study was methodologically limited to large hospitals.

The second limitation was the risk of selection bias. Among 502 medical records, 269 records were reviewed in this study. Because of medical severity, noncooperation or other reasons, 233 participants could not be fully evaluated by SIS. However, there were no significant differences between two groups in their demographics.

The third limitation was in defining impulsive suicide attempters. Based on the literatures reviewed by the authors, impulsive suicide attempts were defined as the sum of two SIS items that subjectively, as well as objectively, evaluated the self-injurious acts. But this method has not been validated. Consistent with previous studies, the impulsive suicide group was represented as having 0 points. In a study by Suominen et al., ${ }^{21}$ points 3 and 4 were defined as being non-impulsive attempts, but in this study, non-impulsive attempts were defined as having 2-4 points. Nevertheless, since scores of 1 were excluded from the analysis, the boundary between the two groups was clear. Additionally, by expanding the range of non-impulsive suicide attempters, the number of participants in this study could be increased. This, in turn, strengthened the statistical power of the present study.

Another limitation was that because no research in South Korea had the same criteria, the result of this study could not be adequately compared with those of other studies. This limitation emphasized the need for a consistent standard to distinguish impulsive suicide attempts.

\section{Conclusion}

Suicide attempters whose self-injurious acts led them to the emergency rooms were evaluated. We evaluated the impulsivity of the attempts and determined the characteristics of individuals driven to suicide by sudden inclinations.

A total of $48.0 \%$ of participants in this study attempted suicide impulsively. In fact, suicide was attempted even during the stage of low-intensity suicidal ideation. A greater proportion of suicide attempts made by elders and those who lived alone were non-impulsive. In the younger age group, however, a greater proportion of suicide attempts were impulsive. Severity and intensity of suicide ideations, reason for suicide, and medical results of suicide attempts were all higher in non-impulsive suicide attempts than in the impulsive group.

\section{REFERENCES}

1. Statistics Korea. Causes of Death Statistics in 2012. Daejeon: Statics Korea; 2013.

2. Jeon HJ, Lee JY, Lee YM, Hong JP, Won SH, Cho SJ, et al. Lifetime prevalence and correlates of suicidal ideation, plan, and single and multiple attempts in a Korean nationwide study. J Nerv Ment Dis 2010;198:643-646.

3. Beautrais AL. Suicide in Asia. Crisis: J Crisis Interv Suicide Prev 2006; 27:55-57.

4. Baca-Garcia E, Diaz-Sastre C, Garcia Resa E, Blasco H, Braquehais Conesa D, Oquendo MA, et al. Suicide attempts and impulsivity. Eur Arch Psychiatry Clin Neurosci 2005;255:152-156.

5. Bertolote JM, Fleischmann A, De Leo D, Bolhari J, Botega N, De Silva $\mathrm{D}$, et al. Suicide attempts, plans, and ideation in culturally diverse sites: the WHO SUPRE-MISS community survey. Psychol Med 2005;35: 1457-1465.

6. Brown LK, Overholser J, Spirito A, Fritz GK. The correlates of planning in adolescent suicide attempts. J Am Acad Child Adolesc Psychiatry 1991;30:95-99.

7. Crosby AE, Cheltenham MP, Sacks JJ. Incidence of suicidal ideation and behavior in the United States, 1994. Suicide Life Threat Behav 1999; 29:131-140.

8. De Leo D, Cerin E, Spathonis K, Burgis S. Lifetime risk of suicide ideation and attempts in an Australian community: prevalence, suicidal process, and help-seeking behaviour. J Affect Disord 2005;86:215-224.

9. Kessler RC, Borges G, Walters EE. Prevalence of and risk factors for lifetime suicide attempts in the National Comorbidity Survey. Arch Gen Psychiatry 1999;56:617-626.

10. Kuo WH, Gallo JJ, Tien AY. Incidence of suicide ideation and attempts in adults: the 13-year follow-up of a community sample in Baltimore, 
Maryland. Psychol Med 2001;31:1181-1191.

11. O'Donnell I, Farmer R, Catalan J. Explaining suicide: the views of survivors of serious suicide attempts. Br J Psychiatry 1996;168:780-786.

12. Perez VW. The relationship between seriously considering, planning, and attempting suicide in the youth risk behavior survey. Suicide Life Threat Behav 2005;35:35-49.

13. Simon OR, Swann AC, Powell KE, Potter LB, Kresnow MJ, O’Carroll PW. Characteristics of impulsive suicide attempts and attempters. Suicide Life Threat Behav 2001;32:49-59.

14. Ha K, Ahn YM, Jeon HJ, Chang SM, Cha B, Youn T, et al. A MultiCenter Study on the Causes and Precipitating Factors of Suicidal Behavior in Suicidal Attempters. Seoul: Korean Association for Suicide Prevention; 2011.

15. Jeon HJ, Lee JY, Lee YM, Hong JP, Won SH, Cho SJ, et al. Unplanned versus planned suicide attempters, precipitants, methods, and an association with mental disorders in a Korea-based community sample. J Affect Disord 2010;127:274-280.

16. Potter LB, Powell KE, Kachur SP. Suicide prevention from a public health perspective. Suicide Life Threat Behav 1995;25:82-91.

17. Jeon HJ. Depression and suicide. J Korean Med Assoc 2011;54:370-375.

18. Rimkeviciene J, O'Gorman J, De Leo D. Impulsive suicide attempts: a systematic literature review of definitions, characteristics and risk factors. J Affect Disord 2015;171:93-104.

19. Williams CL, Davidson JA, Montgomery I. Impulsive suicidal behavior. J Clin Psychol 1980;36:90-94.

20. Baca-Garcia E, Diaz-Sastre C, Basurte E, Prieto R, Ceverino A, SaizRuiz J, et al. A prospective study of the paradoxical relationship between impulsivity and lethality of suicide attempts. J Clin Psychiatry 2001;62:560-564.

21. Suominen K, Isometsa E, Henriksson M, Ostamo A, Lonnqvist J. Hopelessness, impulsiveness and intent among suicide attempters with major depression, alcohol dependence, or both. Acta Psychiatr Scand 1997;96:142-149.

22. Blumenthal SJ, Kupfer DJ. Suicide over the life cycle: Risk factors, assessment, and treatment of suicidal patients. Arlington: American Psychiatric Press; 1990.

23. Anestis MD, Soberay KA, Gutierrez PM, Hernandez TD, Joiner TE. Reconsidering the link between impulsivity and suicidal behavior. Pers Soc Psychol Rev 2014;18:366-386.

24. Bagge CL, Littlefield AK, Lee HJ. Correlates of proximal premeditation among recently hospitalized suicide attempters. J Affect Disord 2013; 150:559-564.

25. Suicide Prevention Act of 2011, Low No. 10516 (March 30, 2011).

26. O'Carroll PW, Berman AL, Maris RW, Moscicki EK, Tanney BL, Silverman MM. Beyond the Tower of Babel: a nomenclature for suicidology. Suicide Life Threat Behav 1996;26:237-252.

27. Freedenthal S. Assessing the wish to die: a 30 -year review of the suicide intent scale. Arch Suicide Res 2008;12:277-298.

28. Posner K, Brown GK, Stanley B, Brent DA, Yershova KV, Oquendo MA, et al. The Columbia-Suicide Severity Rating Scale: initial validity and internal consistency findings from three multisite studies with adolescents and adults. Am J Psychiatry 2011;168:1266-1277.

29. Lim M, Kim SW, Nam YY, Moon E, Yu J, Lee S, et al. Reasons for desiring death: examining causative factors of suicide attempters treated in emergency rooms in Korea. J Affect Disord 2014;168:349-356.

30. Wei S, Liu L, Bi B, Li H, Hou J, Chen W, et al. Comparison of impulsive and nonimpulsive suicide attempt patients treated in the emergency departments of four general hospitals in Shenyang, China. Gen Hosp Psychiatry 2013;35:186-191.

31. DeJong TM, Overholser JC, Stockmeier CA. Apples to oranges?: a direct comparison between suicide attempters and suicide completers. J Affect Disord 2010;124:90-97.

32. Fushimi M, Sugawara J, Saito S. Comparison of completed and attempted suicide in Akita, Japan. Psychiatry Clin Neurosci 2006;60:289-295.

33. Giner L, Blasco-Fontecilla H, Mercedes Perez-Rodriguez M, GarciaNieto R, Giner J, Guija JA, et al. Personality disorders and health problems distinguish suicide attempters from completers in a direct comparison. J Affect Disord 2013;151:474-483.

34. Iribarren C, Sidney S, Jacobs DR Jr, Weisner C. Hospitalization for suicide attempt and completed suicide: epidemiological features in a managed care population. Soc Psychiatry Psychiatr Epidemiol 2000;35:288296.

35. Wei KC, Chua HC. Suicide in Asia. Int Rev Psychiatry 2008;20:434-440.

36. Gunnell D, Frankel S. Prevention of suicide: aspirations and evidence. BMJ 1994;308:1227-1233.

37. McCurry J. Japan promises to curb number of suicides. Lancet 2006; 367:383.

38. Krug EG, Mercy JA, Dahlberg LL, Zwi AB. World report on violence and health. Biomedica 2002;22(Suppl 2):327-336. 